Published as: Stal, C., Van Liefferinge, K., De Reu, J., Docter, R., Dierkens, G., De Maeyer, P., Mortier, S., Nuttens, T., Pieters, T., van den Eijnde, F., van de Put, W., De Wulf, A. (2014). Integrating geomatics in archaeological research at the site of Thorikos (Greece). Journal of Archaeological Science, Vol. 45, pp. 112-125, doi: 10.1016/j.jas.2014.02.018 (IF = 1.889).

\title{
Integrating geomatics in archaeological research at the site of Thorikos (Greece)
}

\section{Abstract}

Archaeological excavation is a destructive process, making accurate, fast and efficient 3D documentation of information essential. With this in mind, our research uses an integrated workflow of topographic measurements and image-based 3D modelling to generate highly accurate reconstructions of archaeological features at the site of Thorikos, Greece. Topographic ground control points and images are acquired using a total station and consumer digital camera respectively, and processed in a highly automated workflow using Structure from Motion and Multiview Stereo reconstruction software. These models were generated on a daily basis in order to map the on-going of a field campaign at this archaeological site in 2012. Moreover, a management system is presented as a consultation and analysis application, enabling the interaction with the 3D models, accompanied with attribute data and metadata. For the efficiency of the management system it was essential to integrate the 3D models in a Harris matrix. This matrix functions as an intermediate between a graphical user interface and the database system. Additionally, two applications of these 3D models are presented, focussing on capacity calculations and in situ mapping (orthophoto mapping) of stone wall remains. The presented management system, the linking of 3D models with excavation data, and the use of 3D models as a scientific tool demonstrate the huge potential of 3D data for archaeological research.

Keywords: 3D modelling; data management; excavation; Geomatics; SfM-MVS; Thorikos

\section{Introduction}

Next to range-based 3D modelling techniques (Pavlidis et al., 2007), image-based 3D modelling is increasingly applied in archaeology and heritage studies in recent years (e.g. Plets et al., 2012; Koutsoudis et al., 2013; Verhoeven et al., 2012). Among these, several studies have already illustrated the potential of image-based 3D modelling for the recording of archaeological excavations (De Reu et al., 2013; De Smedt et al., 2013; Dellepiane et al., 2013; Doneus et al., 2011; Forte et al., 2012; Pollefeys et al., 2000; 2003). Many studies have also shown that 3D modelling is a useful alternative when excavation is not an option or when it is not required. Airborne data acquisition is well known for archaeology and cultural heritage (Hendrickx et al., 2011; Koller et al., 2009; Remondino, 2011). Furthermore, terrestrial laser scanning and close-range photogrammetry are frequently used for the documentation, reconstruction and management of archaeological sites and cultural heritage (Boehler and Marbs, 2004; Tack et al, 2005). The flexibility of both techniques allows to generate high quality 3D models of a wide range of different relicts and artefacts. Even when sites have contaminated or when sites are politically sensitive or environmentally sensitive, it is possible to generate 3D models. 
The ability to perform contact-free measurements is therefore a huge advantage for these techniques. Specifically for close-range photogrammetry, additional advantages of the methodology are the high geometric accuracy of the 3D models, the clear procedure for the recordings and the photorealistic texture. Furthermore, one can proceed from a traditional 2D documentation to a more realistic 3D documentation of the archaeological heritage (e.g. De Reu et al., 2013). And finally, 3D excavation data often have an important and attractive visual character (Hermon, 2008). Because an archaeological excavation is a destructive process (Lucas, 2001), it requires highly accurate visual and scientific recording techniques. Besides its visual value, the scientific value of 3D modelling for the study of archaeological excavations is significant.

Although 3D models have already been used in archaeological research for some years, the construction of these models has sometimes been restricted to the finalisation phase of the archaeological excavation. However, there are examples of the construction of 3D models during excavations, where the advantages of this technique are stress out (Losier et al., 2007; De Reu et al., 2014). An important question we have to answer is how this $3 \mathrm{D}$ data can be made accessible, manageable and usable among the excavators during the excavation and in the post-processing phase of the excavation. Large amounts of data are difficult to manage without a powerful database system, especially when a sufficient infrastructure is absent. Therefore, this paper investigates the implementation of a user-friendly management system for very large 3D data sets, by linking the models with the Harris-matrix of the excavation. The combination of the Harris matrix with $3 \mathrm{D}$ models allows a better insight on the site formation processes. A thorough understanding of the different relations between features in time and space, as presented by these 3D models, is facilitated by a solid data management. Consequently, the human interactions on the site can be understood during the occupancy of the site. Furthermore, we explore two different applications on how the 3D models can be used as base data for spatial analysis related to excavators. First, the calculation of the volume or capacity of the cistern is explored and discussed. These calculations enable the estimation of the volume or capacity of the reservoir. Second, the generation of orthophotomaps, extracted from the 3D models, is explored as a tool for the contour mapping of stone walls. These orthophotomaps are augmenting the traditional 2D manual recordings (e.g. drawings) to be used as an excavation plan during the archaeological fieldwork and enable off-site feature digitalization.

\section{The archaeological site of Thorikos, Greece}

The archaeological site of Thorikos is located on the Velatouri Hill in southeast Attica (Greece, Figure 1), an area known for the presence of rich silver deposits. Since the late Neolithic, the history of the region was largely determined by the exploitation and processing of these mineral resources. Mining activities boomed especially during the Classical (400-323 BC) and the Early Hellenistic period (323250 BC), but also during the Late Classical period (400-500 AD) (Kakavoyiannis, 2005), when a large amount of ore processing workshops consisting of an ore washery, a cistern and living quarters, were scattered over the Laurion. Especially cisterns were vital, since water was an indispensable resource in the silver production process. 
To date, thirteen of such workshops have been recorded in Thorikos. In this paper, focus will be on the so-called 'Cistern no.1 workshop', named after its eye-catching water reservoir and located north of the 'Industrial Quarter' (Figure 2, red ellipse). Thoroughly studied parts of this workshop were excavated during three short campaigns (2010-2012, e.g. Van Liefferinge et al., 2011a) within the framework of a wider research project on water use and management at Thorikos and the Laurion region (Van Liefferinge et al., 2013). Given that the cistern of this workshop is by far the largest water reservoir of the site, its closer study is particularly valuable for this project.

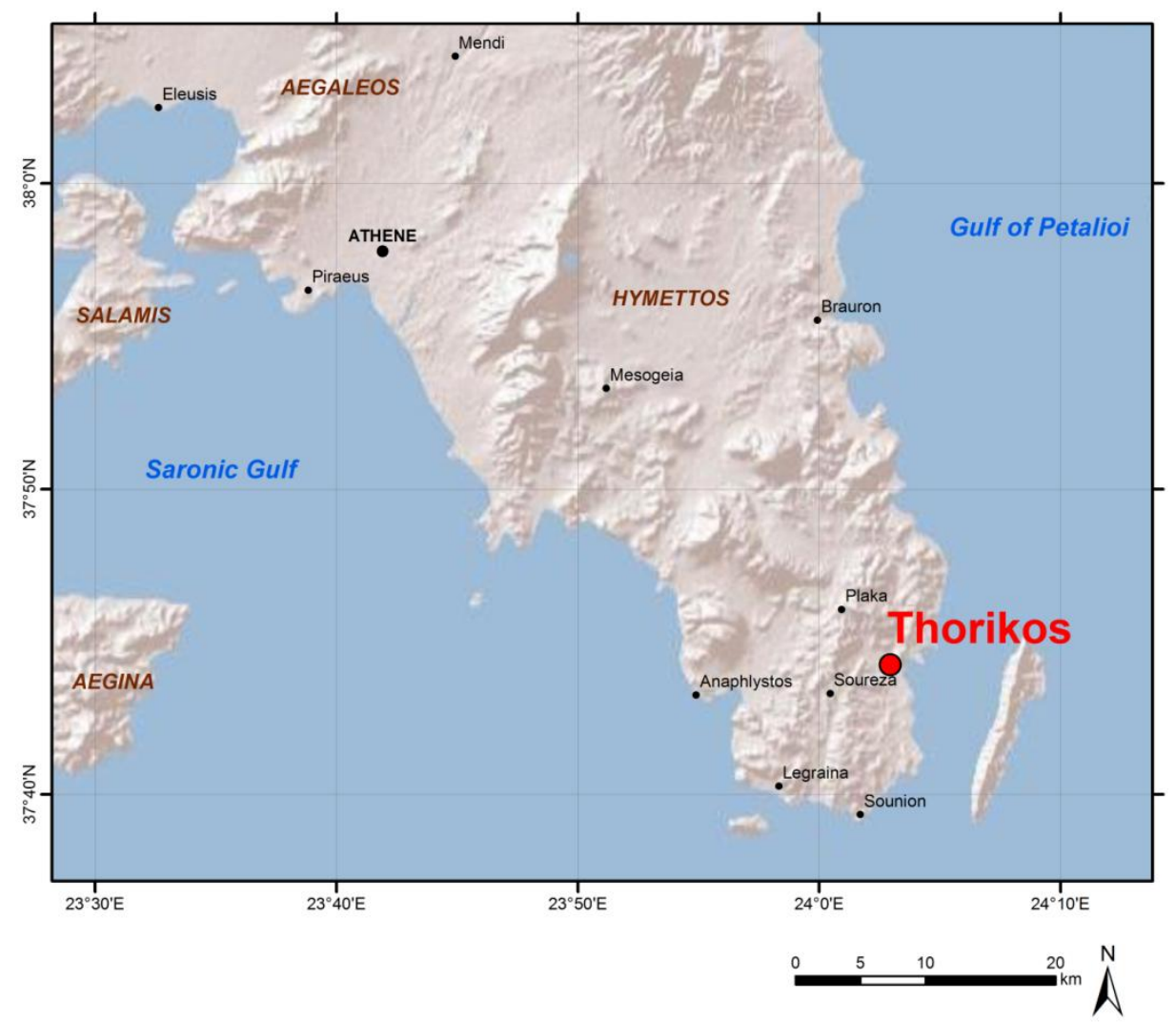

Figure 1: Overview of the Attica province in Greece 


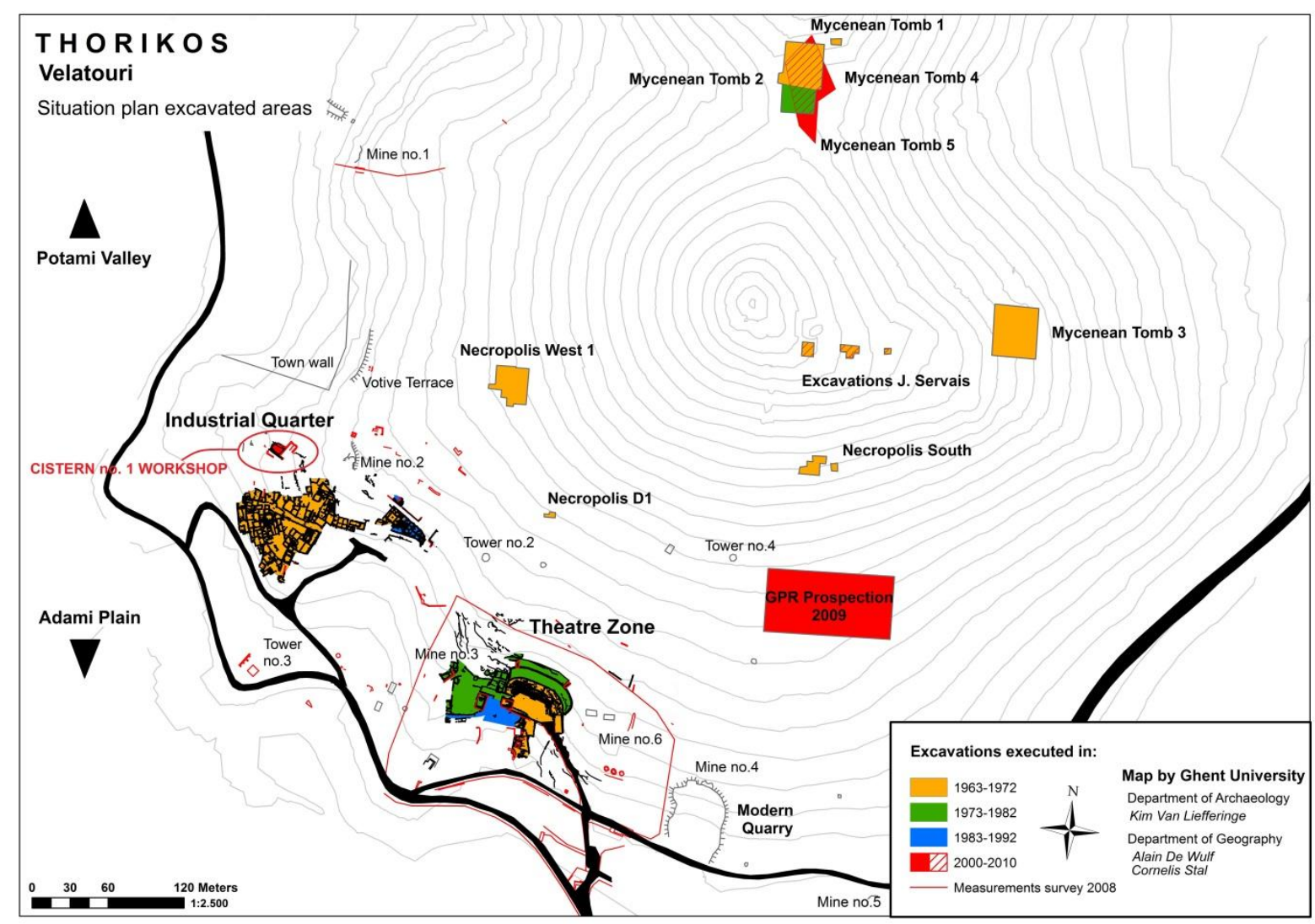

Figure 2: Overview of the Thorikos archaeological site

In the summer of 2012, an intensive archaeological campaign was organized on the ancient site of Thorikos (Greece) by the department of Archaeology of Ghent University (Belgium) and the department of History of the University of Utrecht (the Netherlands). One of the aims of this campaign was to finish the documentation of a large cistern and its surroundings north of the 'Industrial quarter'. To be more precise, work was concentrated on two zones. First, a sounding was dug in the basin of the cistern in order to establish its capacity and date of abandonment. Given its extensive size and the nature of the filling (primarily consisting of large rocks tumbled into the cistern), it was not feasible to clear the entire basin. Therefore, work was concentrated on one zone (A) only (Figure 3). Secondly, a room built against the south wall of the cistern was investigated, with the aim to recover dates on the chronology of the cistern (construction date and date of use). Light would be shed on the use of two overflow channels. Two small trenches were dug in this room, focussing on each of these channels: Zone $\mathrm{F}$ was located in the east and Zone $\mathrm{G}$ in the west. 


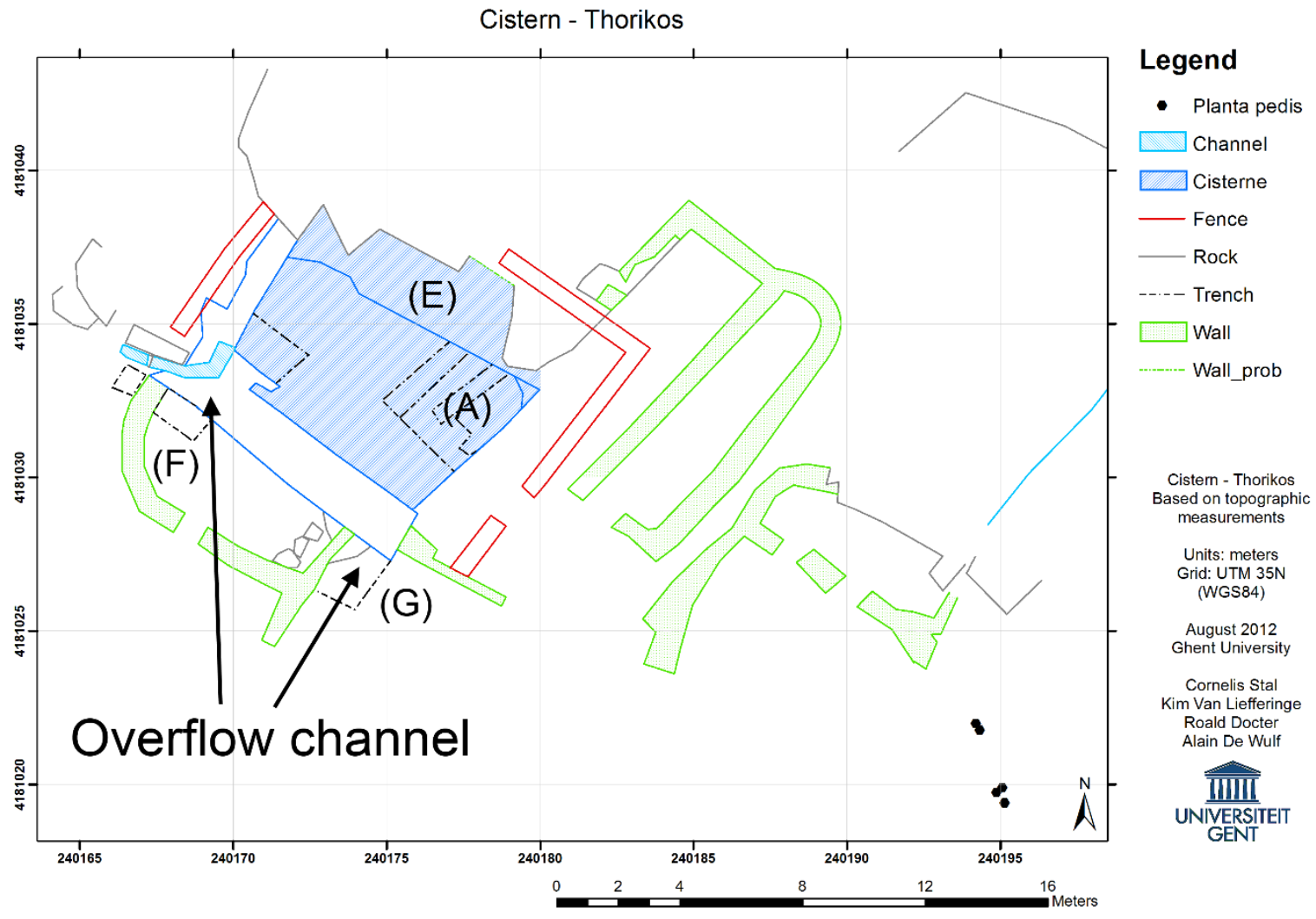

Figure 3: Detailed map of the Cistern no 1 workshop.

In general, the stratigraphic conditions of the excavations in Thorikos are very complex. Being a multi-period site, the majority of the houses and workshops knew multiple occupation phases, during which many adjustments to the buildings were made. Since the investigated zone is no exception, it is imperative to record the excavated contexts meticulously, in order to make a sound interpretation of the stratigraphy. Furthermore, the partial excavation of the cistern involves some problems. The cistern has an irregular outline, with planimetric dimensions of approximately $9.0 \mathrm{~m} \mathrm{x} 7.5 \mathrm{~m}$ and an estimated depth of $4.9 \mathrm{~m}$. The shape of the basin is rather unconventional in comparison with other cisterns in the region. The cistern is subdivided in two parts: the actual basin, which was nicely carved into the rock, and a higher zone in the north, which consists of unadjusted bedrock (E), likely to be used for drawing water out of the basin by low water level. As a result, establishing the capacity of the cistern would not prove to be an easy task. However, by introducing 3D modelling in the archaeological workflow, both discussed issues can be approached in a comprehensive and more accurate way than in the case of traditional archaeological methods.

\section{Virtual reconstruction procedure}

\subsection{Data acquisition}

During the excavation, a systematic series of images was taken and topographic measurements were performed. At the beginning of the campaign, 30 ground control points (GCPs) were materialised 
using a water resistant felt-tip pen and chalk. These markers were put on solid rock and an approximately equal spatial distribution of the GCPs was guaranteed in all directions. Besides, the targets are situated in and around the site, and especially in and around possible areas of special interest. After installing all GCPs, these points were measured using a Trimble S6 robotic total station. A maximal absolute error of $1 \mathrm{~cm}$ for the free stationing was respected, which is acceptable considering the field conditions. This configuration resulted in an absolute error of only a few $\mathrm{cm}$, although the relative accuracy is related to the image pixels, corresponding with a few $\mathrm{mm}$. At the last day of the campaign, an intensive survey was performed in order to get the overall picture of the exposed structures in the immediate neighbourhood of the cistern. It was important that these GCPs were photographed from at least two camera positions, in order to perform a model referencing. The targets were measured using a total station and oriented within the local grid of the Thorikos site. The concrete poles on the edges of this grid had already been measured during previous fieldwork (De Wulf et al., 2000). The transformation parameters for the conversion between the local grid and UTM $35 \mathrm{~N}$ coordinates were defined during the 2000 field campaign. Control measurements on the physical condition of the grid were performed in 2008 (Van Liefferinge et al., 2011b).

A large number of images were taken on a daily basis between 6 and $7 \mathrm{AM}$, in order to avoid cast shadows on the excavated structures. A thorough cleaning was also performed, in order to avoid unwanted elements in the models. The images were taken with a Canon EOS 400D digital single lens reflex camera with a $10.1 \mathrm{Mp}$ CMOS sensor and a Canon EF-S 18-55 mm lens. In order to use the images for 3D modelling, it is required that the images are taken from different positions. Varying the positions will yield a parallax and enables the calculation of object coordinates in a 3D space. A systematic linear movement of the camera around the site (as visualized in Figure 1), is preferred for the fast image processing, but this is not an absolute requirement. Randomly taken images may result in correct 3D models as well, as long as each spot is covered by at least two images (Shashua, A. and Werman, M., 1995), even for very complex structures. A constant quality check should be performed during the acquisition and a surplus of images is advisable.

\subsection{Structure from motion and multi-view stereo software}

The 3D models are based on a Structure from Motion - Multi-View Stereo (SfM-MVS) processing workflow (Lourakis and Argyros, 2009). SfM-MVS is implemented in different software, such as Agisoft PhotoScan, and enables the generation of 3D models based on a large series of images. SfMMVS is a technique to reconstruct the camera acquisition parameters and to calculate a sparse point set of the scene (SfM). Moreover, it is a technique to acquire the 3D geometry of an object, or a series of objects (MVS), using a series of 2D images. Agisoft PhotoScan is used during this project and covers the entire workflow from the impact of the original images to the highly accurate and textured 3D meshes. In order to construct these 3D meshes, three basic steps are performed (Verhoeven, 2011): photo alignment (SfM), geometry reconstruction (MVS) and texture mapping.

The first step in the SfM process is the automatic detection of feature points. Characteristic points have to be localised on each image. Thereafter, corresponding points are detected on other images, resulting in a set of matching points. Different methods have been developed for image matching, e.g. 
methods based on region growing algorithms using seeding points (Heipke et al., 1992), or the use of a GCP database (Chen et al., 2000). The algorithms are based on a least squares estimation, so the solution is obtained by an error minimisation estimator (Gruen, 1985). In order to detect feature points and to perform the image matching, local contrasts or non-equally coloured textures and non-shininess surfaces on the objects are required. This is not a problem for the site of Thorikos, but can be problematic in other projects, e.g. with white limestone or glass. Next to these feature points, the intrinsic image parameters, like the image size and the focal length of the camera, are used to perform the iterative bundle adjustment. The solution of this adjustment corresponds with the best fitting virtual reconstruction of the image scene in a 3D space. By adding GPCs to this scene, external parameters are calculated and accurately metric measurements will be possible in the model.

An initial visualization of the scene structure and the position and the orientation of the images is illustrated in Figure 1, which already gives a good geometrical impression by the 3D visualization of the feature points. This scene represents the zones $F$ and $G$ of the excavated site. The rectangles represent each image used for the reconstruction, numbered by the name of the corresponding image. Based on this figure, it is clear that the requirement of different positions is respected. The numbered dots with flags represent the measured GCPs.

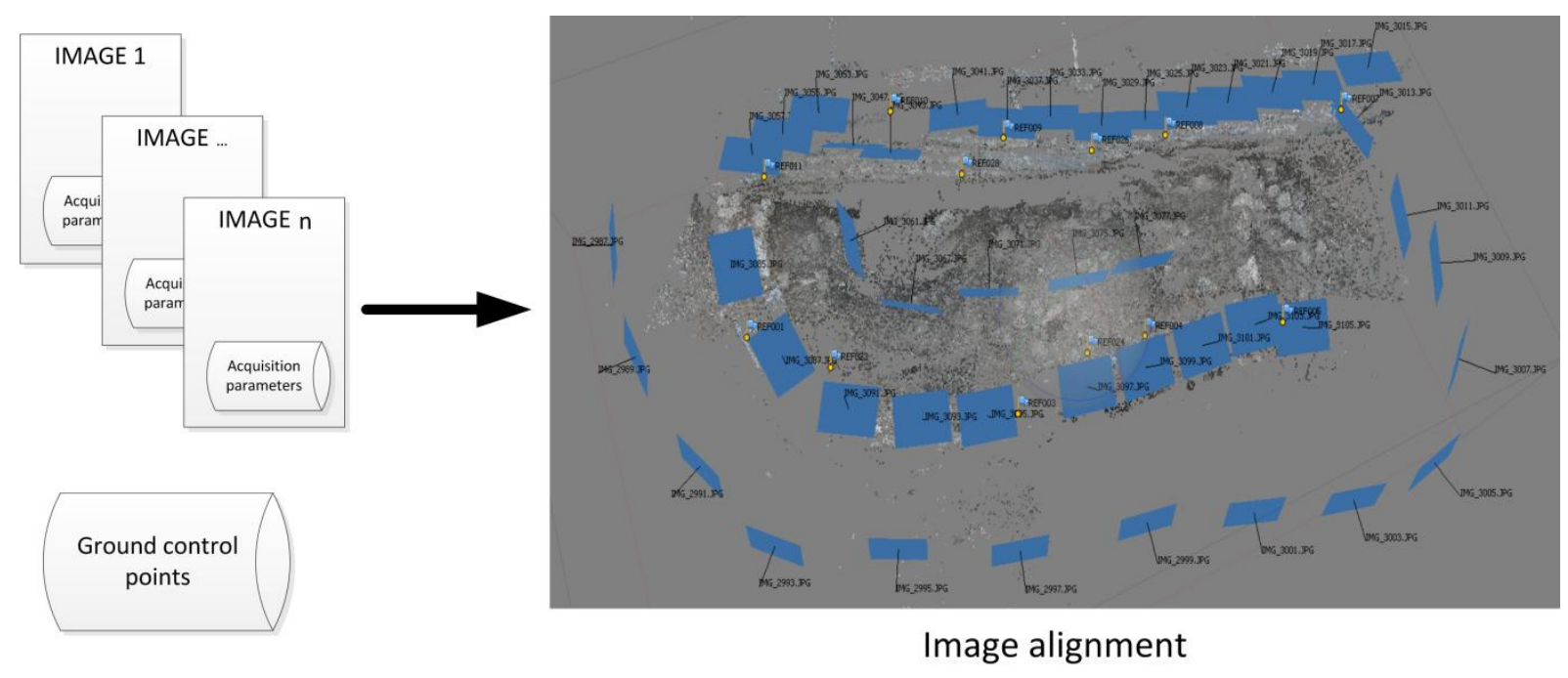

Figure 1: Scene structure with matched feature points and positioned and oriented images

The 3D feature points are not used for the actual 3D reconstruction. A 3D mesh is generated based on the intersection of perspective pixel rays, which is the actual MVS. These rays are projected according to the image frames. The orientation and position of these frames are determined after the image alignment. The focal lengths of the cameras are also used to define the linear projection parameters of the 2D image pixel rays in a 3D space. The result of this project is a series of depth maps, representing the distance between the focal centre of the camera and the intersection of perspective rays. A dense point set is then created by combining these depth maps from differently oriented positions. These points are hereafter triangulated into a mesh. A mesh simplification could be performed for computational performance reasons. More detailed information about SfM-MVS is presented in an extensive discussion by Robertson and Cipolla (2009) and Seitz et al. (2006). 
During the geometric 3D reconstruction, a single colour value, based on averaged colour values of all corresponding pixels from the different images, is assigned to each face in the mesh. A detailed and photorealistic texture map is obtained using uv-mapping (Hülksen et al., 2007). The geometry is textured by projecting the original images on the mesh. Each pixel of the resulting texture map is assigned to a position on the mesh. The colour of this pixel is defined by a function of the weighted value of the corresponding pixels from the original images (Wang et al, 2001). Figure 2 illustrates the concept of UV-mapping, where the geometry of the site (1) is draped with the texture map of the site (2), in order to have the textured 3D mesh (3). The model can be exported as a 3D virtual model in combination with a separate texture map, in order to use the model in other software.

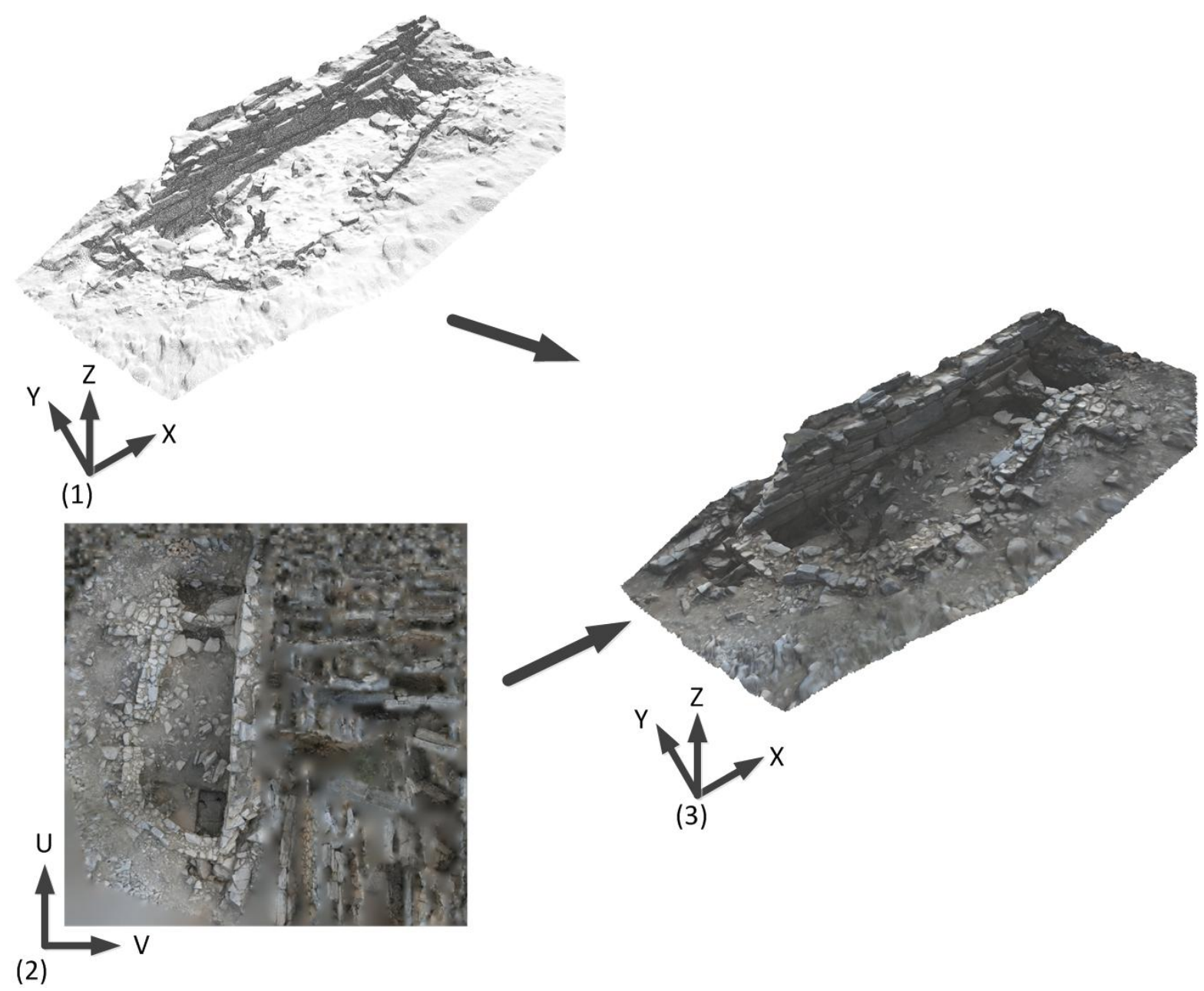

Figure 2: Geometry (1) and texture (2) result in a textured 3D model (3)

Alignment parameters, like the number of feature points, and geometry reconstruction parameters, like the number of faces and accuracy thresholds, were chosen so that the software would give the highest possible quality. However, for the sake of performance of the visualisation of the 3D models in the management system, the 3D mesh was limited to two million faces. The 3D models were described by the Virtual Reality Modelling Language (VRML), with compressed JPEGs as separate texture maps with 100 megapixels. Finally, digital elevation models (DEMs) or orthophotos were generated to facilitate capacity calculations and conventional site interpretations. 


\section{Towards an archaeological management system}

During the campaign, a total of 38 3D models were generated. These models covered the cistern, as well as the room immediately to its south with a different level of detail. Special attention was given to two trial trenches (Zone F and G). Apart from the 3D models, the data was supplemented with attribute data, describing the non-spatial properties of the model. These data were processed in a time dependent manner. It was obvious that this large amount of data required an efficient way of storing and consulting the data. In this context, it was vital that the performance of the management system and the degree of detail of the models were in equilibrium. An example of a random time series, representing the evolution of the excavation in Zone G, is presented in Figure 1. A more detailed application of time series is discussed in section 5 .

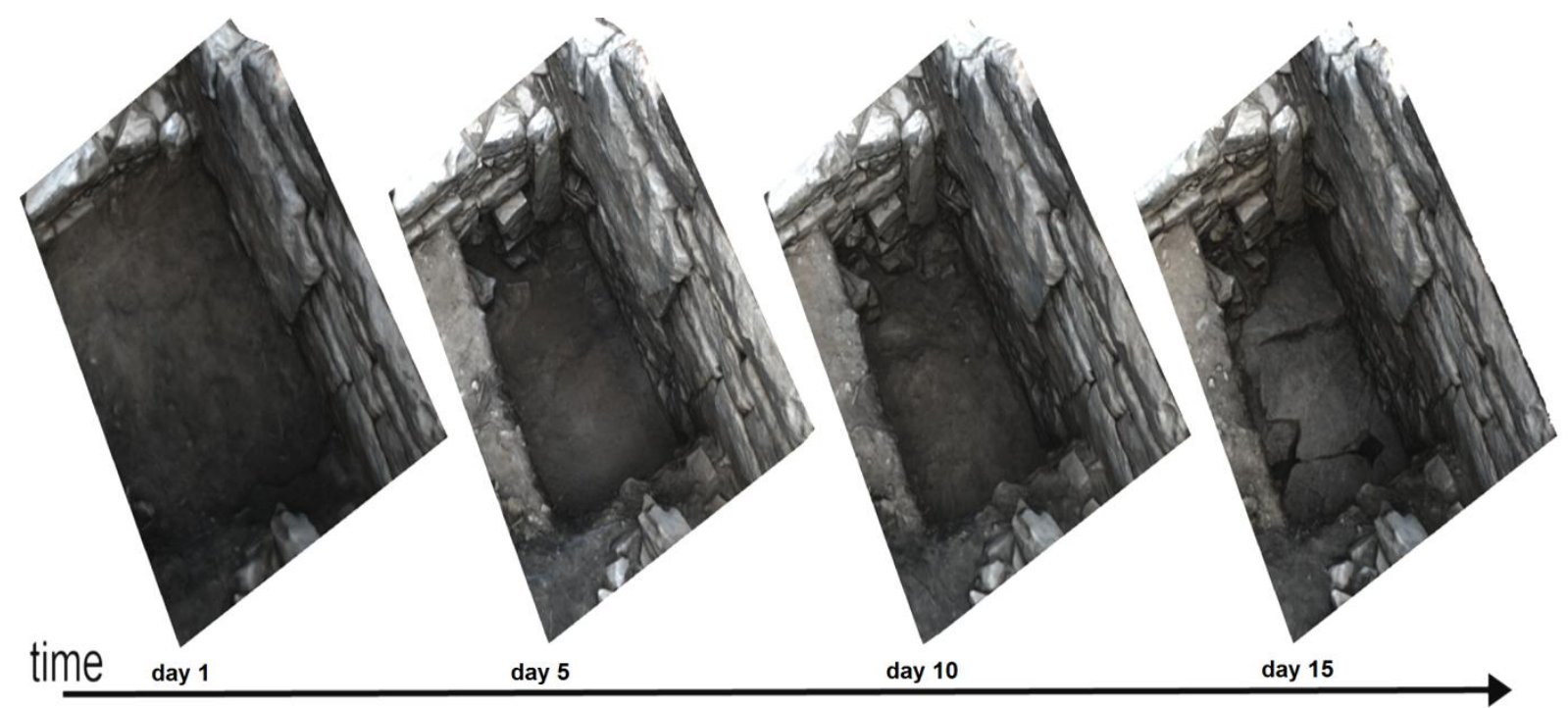

Figure 1: Exemplary time series of Zone G

The graphic user interface (GUI) of the management system was split in four sections (Figure 2, left): the Harris matrix, the actual 3D model, an overview map and a metadata table. The main feature within the management and consultation system was the Harris matrix. This graph-based matrix structure enabled the description of topological and chronological relations between archaeological objects and stratigraphic units (Harris, 1989). During the field campaign, both elements were recorded as contexts and documented by a large number of images. The relations between contexts were modelled and visualised by the creation of a diagram, where nodes represented each context. The sequence of the context and relation between other contexts were represented by directed graphs and by the layered order of the nodes. Some useful software tools exist for the composition of a Harris matrix (Hundack et al., 1997; Traxler and Neubauer, 2008). However, MS Visio was used for the composition, in order to enable the visualisation of the model in a browser, without required plug-ins. The software also enabled to put a hyperlink on every feature within the model, which enabled interaction between the model and different objects in the interface. 

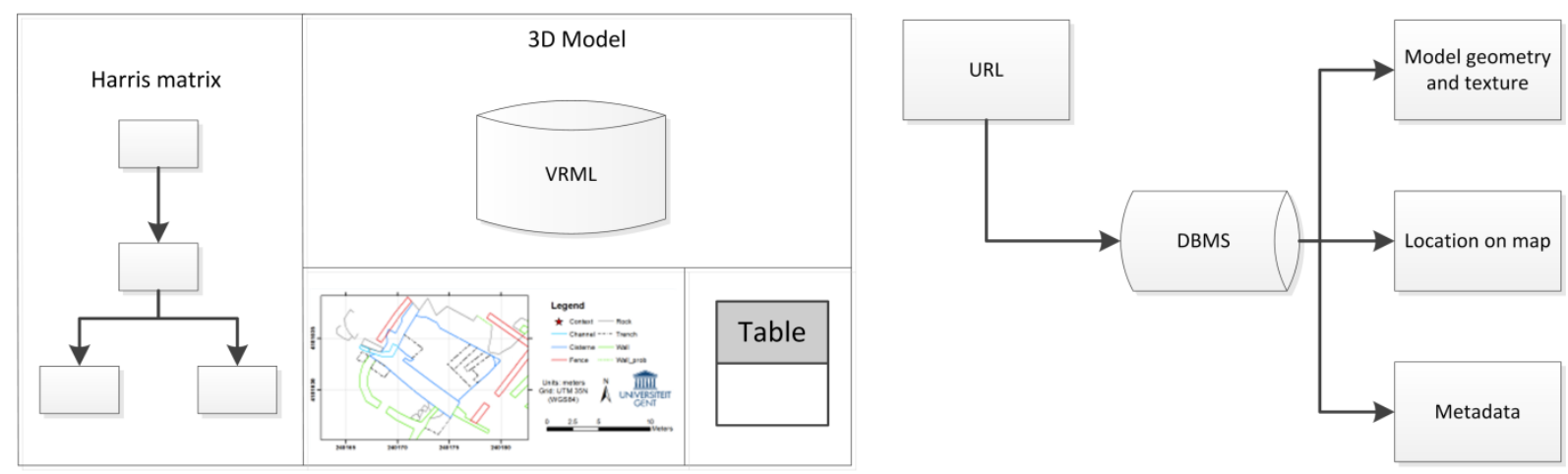

Figure 2: Sketch (left) and conceptual view (right) of the management system

The static Harris matrix provided the actual interaction between the user and the management system. Each node contained a Uniform Recourse Locator (URL) linking features in different databases that were related to the specific context. The URL was processed as a query and controls the 3D model view, the location on the map and the metadata view within the database management system (DBMS, Figure 2, right). The 3D model viewer received an URL and will manage the geometry and texture in the appropriate container, pointing to a certain 3D visualisation plug-in. The URL may optionally contain of a view point definition, defining the virtual camera position, orientation and coordinates of the focus point, where the camera points should aim at. The Virtual Reality Modelling Language (VRML) was chosen to describe the 3D models. Although this language is already succeeded by X3D, VRML is still a frequently used language for the description of virtual reality in archaeology and cultural heritage (Mendes et al., 2012; Rua and Alvito, 2011). Because of its frequent usage, VRML is supported by many commercial and non-commercial 3D viewers. When a specific context is selected, the corresponding 3D model will be loaded using a 3D visualization browser plug-in.

The URL also requests for a map, which is loaded as a static image of the site provided with a marker at the context's location. The map window represents the precise location. In a later stadium, it should be possible to manipulate the database using an interactive map interface. Such system may be implemented as a web feature service (WFS) or web mapping service (WMS). For this pilot study, the static map was used, loaded as portable network graphic (PNG). The base layer of this map was equal to the topographic measurement map of Figure 3. An overview of the architecture of the prototype management system is presented in Figure 3. The Harris matrix is used by the client to request data. Each node is linked with its corresponding context. This context is the main identifier to a date, a series of topographic measurements and metadata. The coordinates are linked with a GIS (Geographic Information System), in order to generate a map. In further steps, the implementation of a WFS or WMS is foreseen, as well as the assignment of a viewpoint to each coordinate (Koutsoudis et al., 2013). 


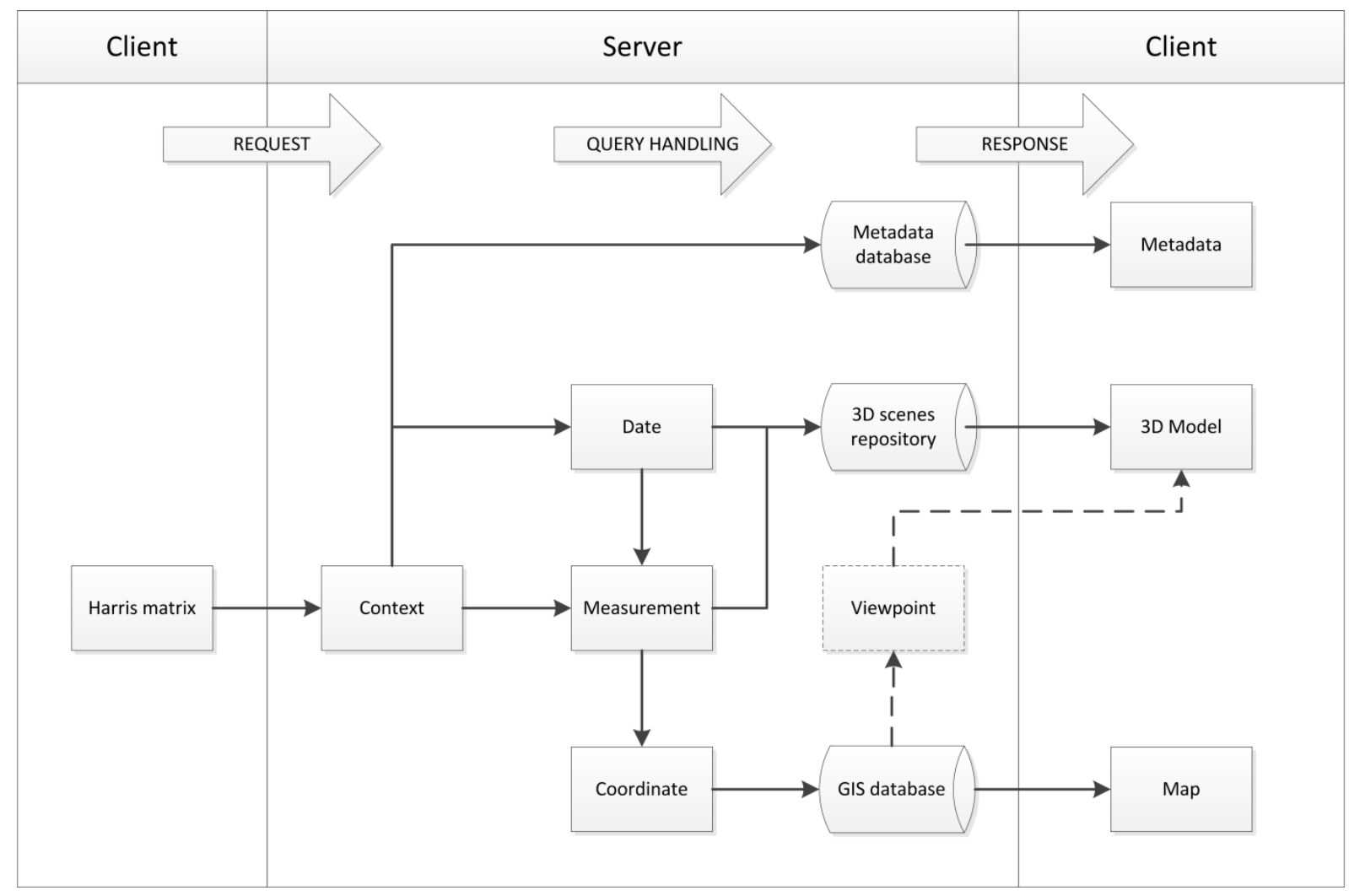

Figure 3: Architecture of the prototype management system

These viewpoints may highlight objects of special interest in the 3D model, but in the current implementation, an overview point suffices. The implementation of these concepts resulted in the actual version of the management system, with a graphical user interface presented in Figure 4.
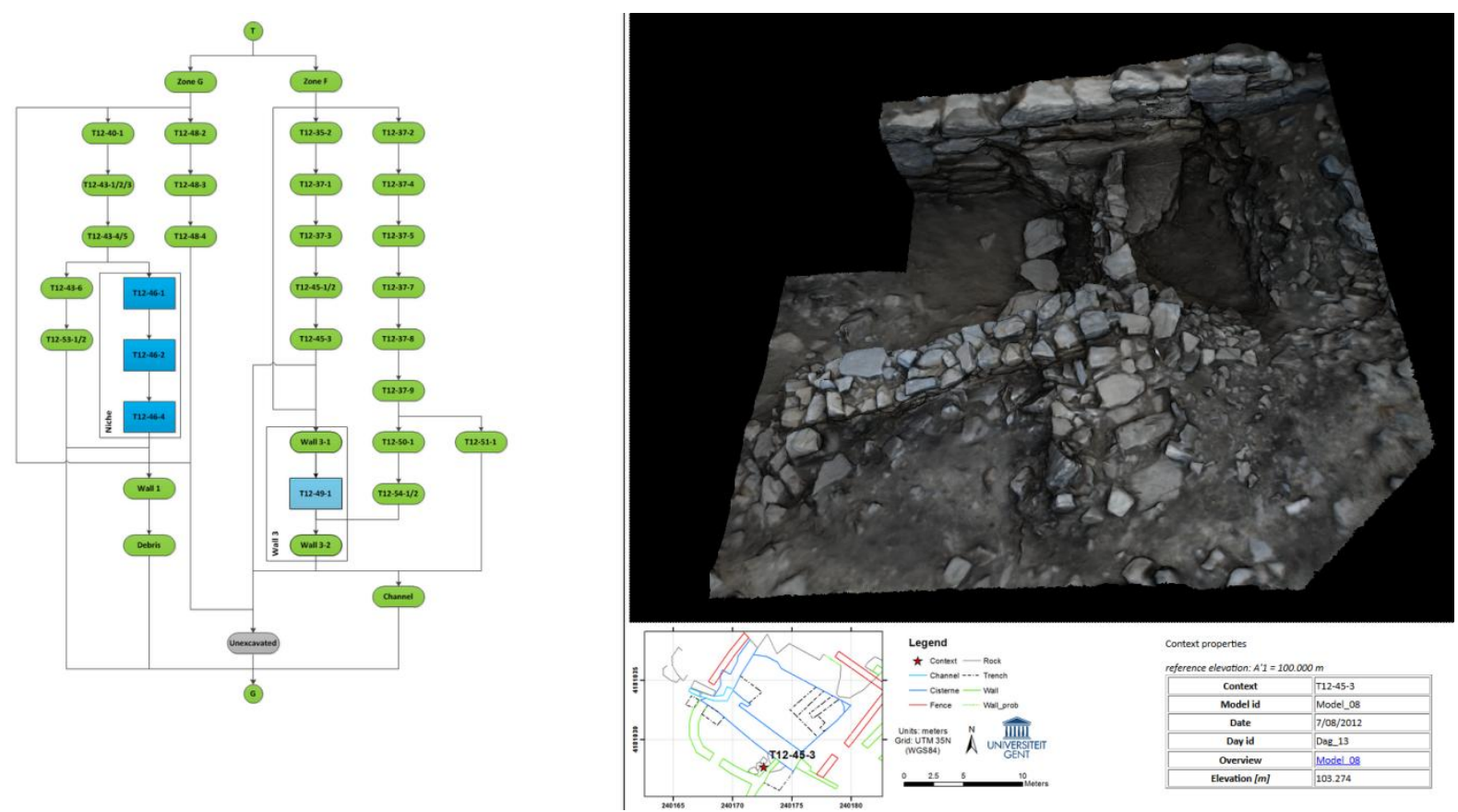

Figure 4: Screenshot of the management system, as implemented in the current version 
In contrast with many other management systems, the presented implementation is not a final product for the analysis and visualisation of the data. During the excavation and the post-processing of the finds, many more data can be added to the system, from the field sheets of the excavated contexts to the artefact database. This requires a large degree of flexibility of the management system for adding, removing and modifying data. This important aspect is respected by implementing more complex protocols, like PHP and SQL.

\section{Other advanced applications}

Besides the advantages of 3D modelling in the archaeological workflow of an excavation, it can also have its use in more specific applications.

\subsection{Capacity calculation of the cistern}

In the context of this excavation and the wider research questions, a capacity calculation was a particularly valuable technique. As mentioned above, a careful water management was crucial for the metallurgical activities at Thorikos. A definition of the capacity of the site's largest water reservoir will contribute to our knowledge on the production output of the individual workshop and on a larger scale, of Thorikos as an industrial site.
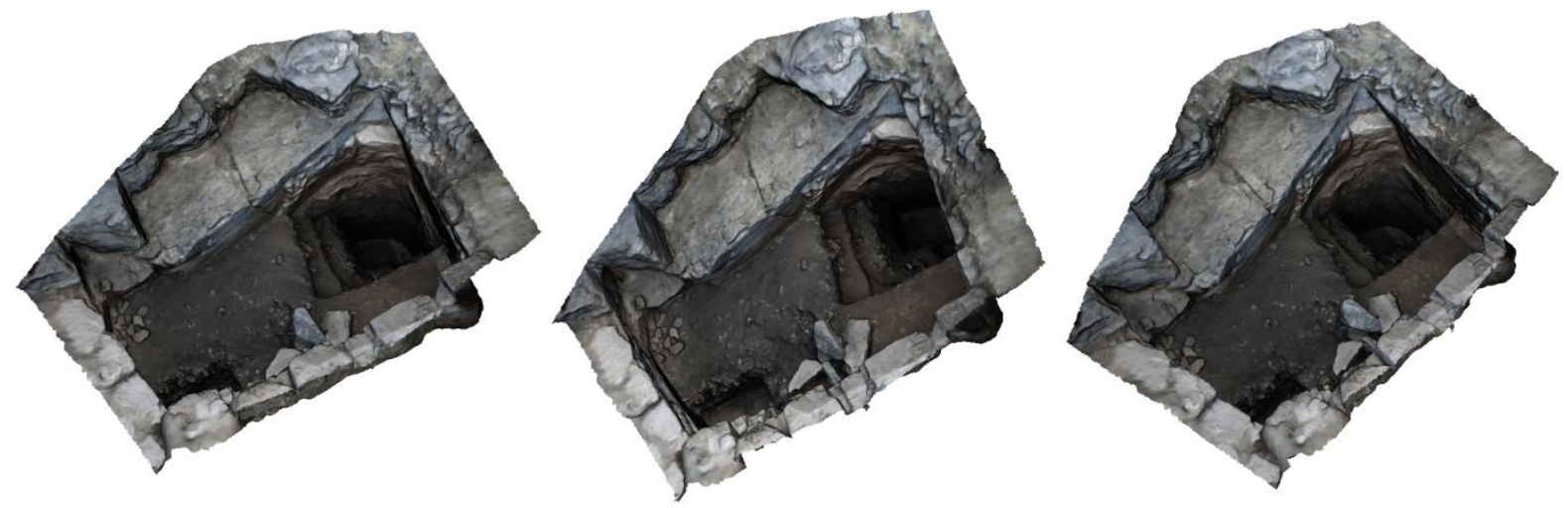

Figure 1: Screenshots of 3D model of the cistern after partial excavation (for dimensions: Figure 2)

Figure 1 shows several viewpoints of the 3D model of the cistern, built by using image-based 3D modelling and total station measurements. Since the 3D model was constructed using a series of GCPs, a horizontal reference plane could be defined. The elevation values were then projected on this plane, in order to generate a Digital Elevation Model (DEM). This DEM and some characteristic elevation points are visualised in Figure 2. Elevations (or depths) in this figure are related to the original surface, which is used as a reference level. By converting the 3D model to a DEM, the geometric complexity was reduced to 2.5D. This implies that every planimetric position had only one elevation value. Thus, it was not possible to model overhanging parts in the DEM and volumes covered by these overhangs were not included in the total capacity calculation. 
The cistern can be divided into two zones, both used for water storage, as demonstrated in Figure 2. The first zone (I) was excavated until an elevation of $-6.0 \mathrm{~m}$, where the bottom of the cistern was reached, corresponding with zone A in Figure 2. Other points in this zone, with an elevation of up to $3.5 \mathrm{~m}$, remained unexcavated. Based on other fully excavated cisterns elsewhere in the region, it was assumed that the elevation of the entire bottom of the cistern is equal to $-6.0 \mathrm{~m}$. The second zone (II) consisted of bare rock with elevations between $-2.5 \mathrm{~m}$ and $-1.7 \mathrm{~m}$ and corresponds with zone $\mathrm{E}$ in Figure 2. The total capacity was calculated as the sum of the two separate volumes of zone (I) and zone (II), with an a priori reference plane at an elevation of $-1.1 \mathrm{~m}$. This was the elevation of the highest stone at the southern partition wall. It was assumed that this reference plane is horizontal and perpendicular to the gravity normal.

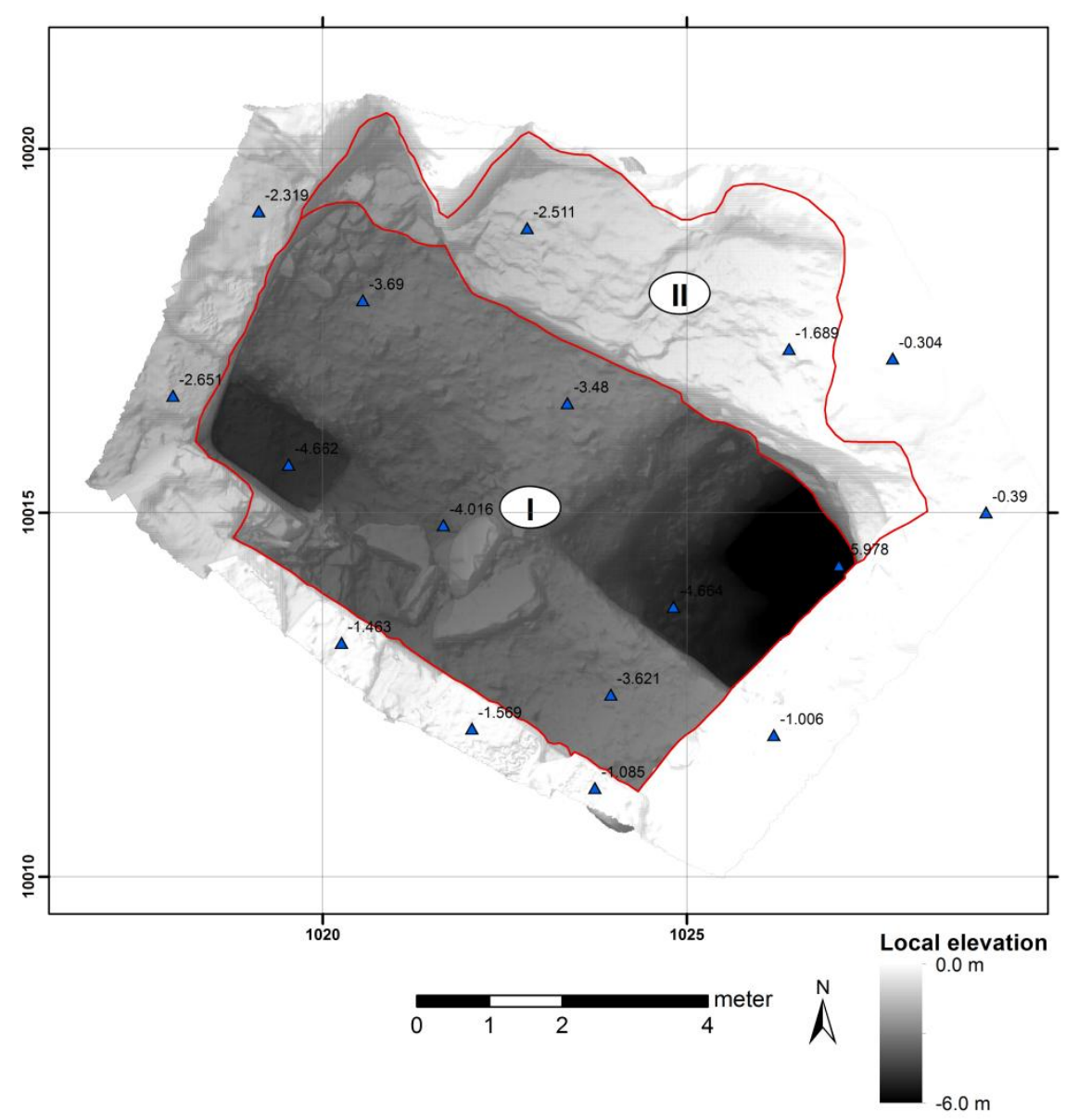

Figure 2: Digital elevation model of the cistern and zonal division (grid: local coordinates)

The volume of zone (I) was calculated by taking the area of the convex hull of this zone, which was $39.02 \mathrm{~m}^{2}$. The a priori maximal elevation was $-1.1 \mathrm{~m}$, whereas the minimal elevation was $-6.0 \mathrm{~m}$, corresponding with a range of $4.9 \mathrm{~m}$. The volume of zone (I) was then equal to $191.2 \mathrm{~m}^{3}$. The solid rock surface of zone (II) was totally excavated and sloping, so a grid-wise volume calculation was used. For each pixel within the convex hull, the difference between the elevation of that pixel and the elevation of the reference plane was calculated. The resolution of the DEM was equal to $0.01 \mathrm{~m}^{2}$ and the total area of zone (II) was equal to $17.9 \mathrm{~m}^{2}$. The volume of zone (II) was thus equal to the sum of all elevation differences times the area of the zone, corresponding with $18.42 \mathrm{~m}^{3}$. Consequently, the total capacity of the cistern was equal to $209.6 \mathrm{~m}^{3}$. 


\subsection{Detailed wall mapping}

The composition of stone suffers from important errors, which are caused by, inter alia, erroneous grid construction and usage, human subjectivity and, environmental conditions in terms of temperature, humidity and comfort, etc.
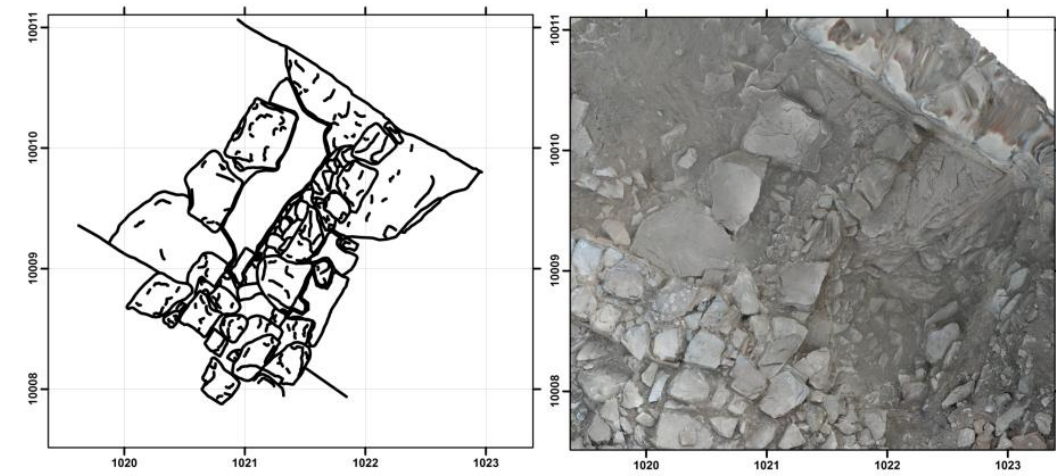

${ }_{1020}$

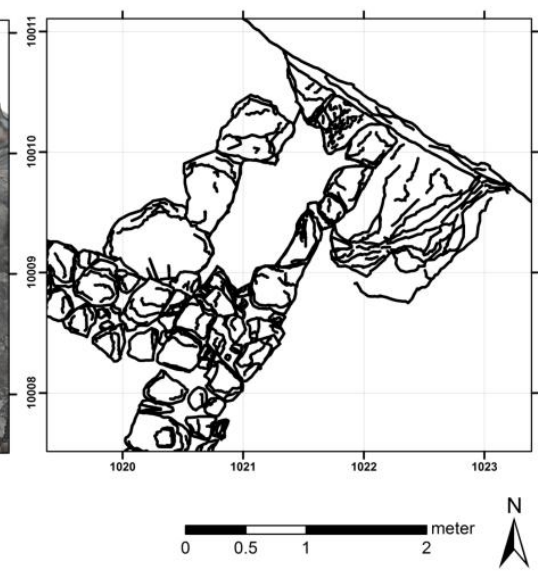

Figure 12: Stone plan and orthophoto (middle) of the intersecting area of Wall 2 and Wall 3, manual (left) and orthophoto digitising (right)

As mentioned in section 3, one of the products of a SfM-MVS workflow is an orthophoto. In contrast with a conventional image, containing a central perspective, the advantage of such an image is the absence of geometrical deformations, caused by the orthogonal projection of the image on a DEM. As a result, orthophotos are very useful for in situ mapping. Characteristic lines were traced manually or with the use of edge detection filters. The result of this procedure is demonstrated in Figure (right), where the lines represent the stone outlines.

A visual comparison between the manual stone mapping and orthophoto-based stone mapping states the difference of the two approaches. In spite of the much smoother polylines in the manual map, a misalignment with the orthophoto was apparent. This is most clear in the southernmost part of the image. Furthermore, several break lines or marginal ridges were not or not correctly mapped, due to the often difficult conditions on field (visibility, heat, time, etc.) ... The orthophoto-based vector map had a much better correspondence with the degree of detail of the orthophoto itself. This stresses out the user dependency of the results of both techniques. However, since these maps could be made in post-processing, and thus off-site, the extra time required for the orthophoto generation is partially compensated by a significant saving of time during the excavation itself.

\section{Discussion}

Virtual 3D models were generated systematically on a daily base sequence, in order to evaluate the excavation process and to place the archaeological contexts in a correct spatial neighbourhood. During the campaign, almost 3000 images were taken and topographic measurements were performed. These data were used for the construction of 38 digital 3D models of the excavation site. As demonstrated in this paper, the advantages of using 3D models are manifold and apply on all phases of the 
archaeological workflow. In contrast with conventional archaeological data processing, the entire processing chain was digital and the research results in a systematic DEM of the evolution of the excavation during the three-week campaign. The models allowed the archaeologist to perform intensive research on different contexts in a digital 3D environment, even when this context had been removed. As a result, the presented DEMs were useful for in situ documentation, interpretation and management. Besides, the absolute orientation of the models by topographic means enabled geometric evaluation archaeological objects in post processing, the definition of topological relations between contexts and the construction of a wide range of derivatives, like orthophoto plans, wall drawings and contour line maps.

The 3D data facilitated to correlate, re-assess and re-assembly the sometimes fragmented information obtained during the excavation and the post-processing of the acquired data (Katsianis et al., 2008). Purely practically speaking, it guaranteed a smoother continuation of the activities on site, since a large part of the drawing was consciously postponed to the post-processing phase. Especially in Mediterranean excavations, where a regular day of an archaeological campaign is usually divided in excavating before noon and data processing in the afternoon, this methodology could easily be adopted. Newly recorded walls were for example photographed during the excavation in the early morning and subsequently modelled and drawn in the office in the afternoon. Furthermore, excavation units could more easily be investigated. Measurements could be performed from all angles, section cuttings could fluently be created and volumes calculated. Vertical sections were an extremely important tool in archaeology to record stratigraphic sequence (Zhukovsky, 2002). 3D models enabled to cut cross-sections off-site and wherever they were considered to be profitable, whereas on field only a restricted amount of cross-sections can be created due to time constraints. Another important advantage of the use of 3D models is the fact that visual obstacles can be removed easily. The only requirement is that the study object behind the obstacle is photographed in accordance with the rules (e.g. enough contrast, overlap and different acquisition positions or non-zero baselines) of imagebased modelling. An example from this case study is the fact that the Greek Heritage Authorities were reluctant to grant the removal of olive tries on the site. One of these trees is in the middle of zone F, obscuring some important structures in a wider context from different viewpoints. It is easy to ignore this tree during the $3 \mathrm{D}$ reconstruction, resulting in an obstacle-free visualisation. This concept is clearly visible in Figure 1, where the original photograph (left) and the 3D reconstruction (right) correspond with the same viewpoint.
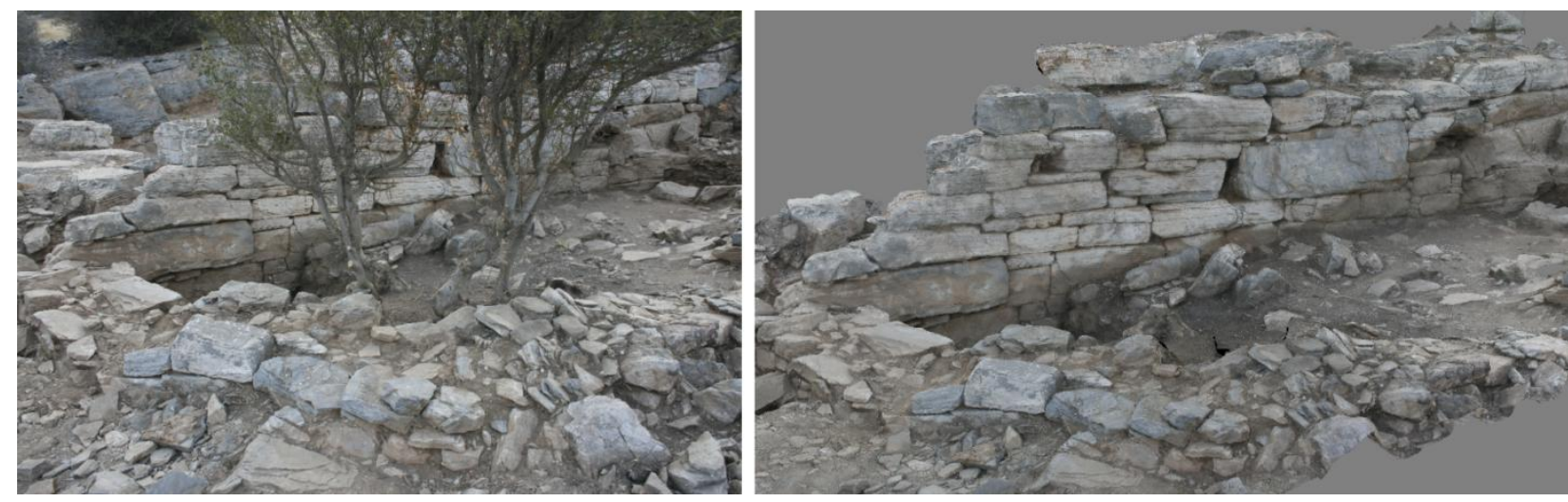

Figure 1: Photograph (left) and 3D reconstruction (right) of zone F, demonstrating the advantageous effect of virtual obstruction removal 
It must be mentioned that the proposed methodology may suffer from some drawbacks. The environmental conditions at the Greek site oblige to take the images at a limited time frame at dawn and after carefully cleaning the site. This implies that the excavation should be put on hold for a few moments. The quality of the markers has to be verified frequently and all objects on the site have to be terrestrially photographed. This is also an advantage of the methodology, since this systematic coverage is guaranteed with high accuracy and high resolution. Furthermore, since it is not preferred to perform the excavations as a function of the 3D data acquisition, the images can also be taken using sun screens in order to avoid shades. In the case of the Thorikos excavation in 2012, the working area was limited and could be fully covered by terrestrial images. If the site has larger dimensions or if the objects on the site are too complex to fully cover terrestrially, the use of a low cost Unmanned Aerial Vehicle (UAV) would be a very useful alternative (Pérez et al., 2013). Such a flying platform extends the spatial extend of the image acquisition and also enables to cover difficultly reachable areas. Notwithstanding these two different acquisition methodologies, the result is a series of images that have to be processed using the same workflow. In our case, both the site cleaning and the acquisition of the images required only twenty to thirty minutes. The excavation started immediately after the image acquisition, altering the entire scene. The image acquisitions should be immediately successful, as the recording can only be done once. This requires profound training and photogrammetric expertise.

The post-processing of the images is frequently considered as a time consuming process, motivated by the performance of conventional photogrammetric procedures. Earlier research demonstrates that the image processing workflow require a few minutes to a few hours, depending on the desired processing parameters (Doneus et al., 2011). After selecting correct images, defining GCPs on the images and fine-tuning the parameters, most of this time goes to the reconstruction itself, which does not require human interaction but is fully automated.

During many excavation campaigns, a total station and a digital camera are standard equipment. Consequently, no extra on-site hardware and resulting costs are needed. Agisoft Photoscan, which is commercial software, was used for the 3D reconstruction and requires a powerful computer. In fact, this is the only additional cost, but one could also opt for open-source software (Kersten and Lindstaedt, 2010). Next to the expertise on the data acquisition, a thorough knowledge about the processing is indispensable. Recent publications about the use of 3D modelling in archaeological research indicate 3D modelling is already applied for entire sites (Verhoeven et al., 2012), but also for soil profiles (De Reu et al., 2014) or rock art (Fritz and Tossello, 2007). These projects are just an example of the much recent projects where 3D models and digital orthophotos facilitate archaeological research.

Capacity calculations were employed to estimate volumes of soil samples in relation to the excavation unit volume and to calculate the amount of earth still to dig (Losier et al., 2007). The geometric accuracy of these products is high, especially in comparison with many manually generated equivalents. Within the framework of the Thorikos excavation, it proved to be a particularly useful tool to define the capacity of 'Cistern no.1'. Due to the restricted time frame in which the campaign had to be conducted, it was only possible to clear one zone of the basin (zone A). Nonetheless, the 
model allowed the creation of an accurate assessment of its capacity. An extra advantage of working with image-based 3D modelling was that the texture and colour of the soil and archaeological features is also recorded. Investigating archaeological contexts through 3D models was therefore not only more accurate, but also more realistic. Up-to-date 3D information about the progress of the excavation is essential for various reasons:

- It facilitates the decision making about the further continuation of the campaign: new areas of interest, additions to existing areas or even adjustments on the excavation strategy can be defined by the interpretation of the latest DEMs and orthophotos.

- It enables fast exchange of information between the excavators and finds processors: on the one hand, excavators can assign their findings to specific context by creating a digital link between the feature and the model. On the other hand, finds processors can directly implement the results of their analysis in the model allowing a better focus on specific areas of the site.

- It allows the extension of a temporal GIS: contexts are modelled as closed 3D models. When a Harris matrix is used as a conceptual model of the topological relations between features, the 3D GIS with temporal attribute forms the physical representation of the site. Temporal attributes enables the easy definition of relations between different features and they may assist in a better understanding of the spatial distribution of phenomenon.

The large number of 3D models requires the implementation of some management environment, in order to enhance flexibility of the consultation and analysis of the models. Parallel with the daily construction of the 3D models, a Harris matrix was generated for the documentation of different topological and chronological relations. Since the same relations exist between different successive 3D models, it would be obvious to generate a link between the Harris matrix and the virtual reconstructions. Not only is the Harris matrix simultaneously generated during the campaign, its interpretation is common practice in archaeological sciences. As a result, the conceptual file structure of the models within the matrix does not require much effort for the field expert. Implementing the system in an online server-client based environment improves the efficiently of the research work, as well as the visibility of the Thorikos-project for a wider public.

\section{Conclusion}

In this paper, we demonstrated the use and management of archaeological 3D data. The 3D data were collected during an excavation campaign of the Cistern no.1 workshop in Thorikos, Greece in 2012. It involved topographic measurements and a large series of images. The data were processed in a SfMMVS based workflow, resulting in a series of daily 3D models of specific areas of interest. The large number of models enabled the monitoring of the course of the excavation in a highly detailed and accurate way, enhancing the interpretation of the contexts. However, the efficient and clear management of these data was indispensable. We presented a management system focussing on the requirements of fast model visualisation, clear metadata consultation and the ability to use the data for advanced analysis. Using the system's architecture, it was also possible to add, remove and modify 
data in a transparent way. The implementation of more advanced protocols, like PHP and SQL, in the presented prototype, improves the performance of the system and will be done in the near future.

We also demonstrated the advanced use of 3D models to answer archaeological research questions or to improve the quality of the archaeological excavation documentation. Two examples were presented, focussing on capacity calculations and in situ mapping of stone wall remains. Within the framework of the Thorikos site, the calculation of the capacity of the cistern was essential for the research on the water management within its industrial context. An accurate and mobile procedure of calculating capacity was therefore indispensable. The presented SfM-MVS approach fitted these requirements. A second application was the use of SfM-MVS-based orthophotos for mapping. Based on a visual comparison, the orthophoto-based digitalisation of stone outlines tended to give significantly better results than its manual-visual counterpart.

\section{Acknowledgement}

This research is part of the research project "3D CAD modelling of spatial architectural volumes, using terrestrial laser scanning and LiDAR" (G082309N of the Fund for Scientific Research Flanders (FWO). This project is promoted by Prof. Dr. Ir. A. De Wulf, Prof. Dr. Ph. De Maeyer, Prof. Dr. N. Van De Weghe, Prof. Dr. S. Gautama, Prof. Dr. R. De Meyer and Arch. M. Mattys. The authors would like to acknowledge the support of FWO-Flanders.

\section{References}

Boehler, W., Marbs, A., 2004. 3D scanning and photogrammetry for heritage recording: a comparison, 12th Conference of Geoinformatics - Geospatial Information Research: Bridging the Pacific and Atlantic, Gävle, Sweden, pp. 291-298.

Chen, L., Lo, C., Liu, C., Chen, A., 2000. Orientation modeling by matching image templates of a GCP database, 21th Asian Conference on Remote Sensing, Kuala Lumpur, Malaysia, pp. 6 (on CDROM)

De Reu, J., Plets, G., Verhoeven, G., De Smedt, P., Bats, M., Cherretté, B., De Maeyer, W., Deconynck, J., Herremans, D., Laloo, P., Van Meirvenne, M., De Clercq, W., 2013. Towards a threedimensional cost-effective registration of the archaeological record. Journal of Archaeological science 40(2), 1108-1121.

De Reu, J., De Smedt, P., Herremans, D., Van Meirvenne, M., Laloo, P., De Clercq, W., 2014. On introducing an image-based 3D reconstruction method in archaeological excavation practice. Journal of Archaeological Science 41 (January), 251-262.

De Smedt P., Van Meirvenne M., Herremans D., De Reu J., Saey T., Meerschman E., Crombé P., De Clercq W., 2013. The 3-D reconstruction of medieval wetland reclamation through electromagnetic induction survey. Scientific Reports, 3 (1517). pp. 5. 
De Wulf, A., Van Herck, T., De Dapper, M., De Vliegher, B.M., 2000. Analysis of the efficiency in archaeology of GPS satellite surveying versus classical surveying using totalstations: Applications in the Thorikos region and on the Pyrgari (Greece), in: Vermeulen, F., De Dapper, M. (Eds.), Geoarchaeology of the Landscapes of Classical Antiquity, pp. 19207.

Dellepiane M., Dell’Unto N., Callieri M., Lindgren S., Scopigno R., 2013. Archeological excavation monitoring using dense stereo matching techniques. Journal of Cultural Heritage 14 (3), 201-210.

Doneus M., Verhoeven G., Fera M., Briese C., Kucera M., Neubauer W., 2011. From Deposit to Point Cloud - A Study of Low-Cost Computer Vision Approaches for the Straightforward Documentation of Archaeological Excavations. In: Čepek A. (Ed.). XXIIIrd International CIPA Symposium, Prague, $12-$ 16 September 2011. Geoinformatics, 6. Faculty of Civil Engineering, Czech Technical University, Prague: 81-88.

Forte M., Dell’Unto N., Issavi J., Onsurez L., Lercari N., 2012. 3D Archaeology at Çatalhöyük. International Journal of Heritage in the Digital Era, 1 (3): 351-378.

Fritz, C., Tosello, G., 2007. The hidden meaning of forms: methods of recording Paleolithic parietal art. Journal of Archaeological Method and Theory 14 (1), 48-80.

Gruen, A., 1985. Adaptive least squares correlation: a powerful image matching technique. South Africa Journal of Photogrammetry, Remote Sensing and Cartography 14 (3), 175-187.

Harris, E., 1989. Principles of archaeological stratigraphy. Academic Press, London, UK.

Heipke, C., Kornus, W., Strunz, G., Thiemann, R., Colomina, I., 1992. Automatic photogrammetric processing of Spot imagery for point determination, DTM generation and orthoprojection. International Archives of Photogrammetry and Remote Sensing 29 (4), 465-471.

Hendrickx, M., Gheyle, W., Bonne, J., Bourgeois, J., De Wulf, A., Goossens, R., 2011. The use of stereoscopic images taken from a microdrone for the documentation of heritage - An example from the Tuekta burial mounds in the Russian Altay. Journal of Archaeological Science 38 (11), 2968-2978.

Hermon, S., 2008. Reasoning in 3D: a critical appraisal of the role of 3D modelling and virtual reconstructions in archaeology. in: Frischer, B., Dakouri-Hild, A. (Eds.), Beyond Illustration: 2D and 3D Digital Technologies as Tools for Discovery in Archaeology, BAR International Series 1805, Archaeopress, Oxford, pp. 35-44.

Hülksen, F., Eckes, C., Kuck, R., Unterberg, J., Jörg, S., 2007. Modeling and animating virtual humans for real-time applications. International Journal of Virtual Reality 6 (4), 11-20. 
Hundack, C., Mutzel, P., Pouchkarev, I., Thome, S., 1997. ArchE: A graph drawing system for archaeology, in: Di Battista, G. (Ed.), Graph Drawing. Springer-Verlag, Heidelberg, Germany, pp. 29302.

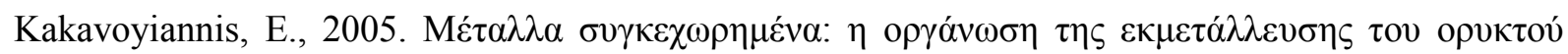

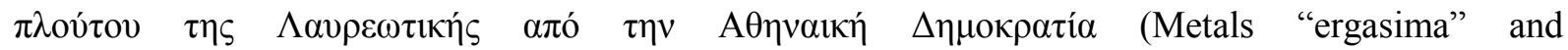
"synkechoremena". The exploitation of the mineral wealth of the Lavrion mines by the Athenian Democracy). Archaeological Receipts, Athens, Greece.

Katsianis, M., Tsipidis, S., Kotsakis, K., Kousoulakou, A., 2008. A 3D digital workflow for archaeological intra-site research using GIS. Journal of Archaeological science 35(3), 655-667.

Kersten, T., Lindstaedt, M., 2010. Reality-based 3D modeling, segmentation and web-based visualization, in: Ioannides, M. (Ed.), 3rd International Euro-Mediterranean Conference on Digital Heritage (EuroMed 2010). Springer, Limassol, Cyprus, pp. 140-152.

Koller, D., Frischer, B., Humphreys, G., 2009. Research challanges for digital archives of 3D cultural heritage models. Journal on Computing and Cultural Heritage 2 (3), 1-17.

Koutsoudis, A., Stravroglou, K., Pavlidis, G., Chamzas, C., 2013. 3DSSE: A 3D scene search engine, exploring 3D scenes using keywords. Journal of Cultural Heritage 13 (2), 18194.

Koutsoudis A., Vidmar B., Ioannakis G., Arnaoutoglou F., Pavlidis G., Chamzas C., 2013. Multiimage 3D reconstruction data evaluation. Journal of Cultural Heritage: http://dx.doi.org/10.1016/j.culher.2012.1012.1003.

Losier, L.-M., Pouliot, J., Fortin, M., 2007. ED geometrical modeling of excavation units at the archaeological site of Tell 'Acharneh (Syria). Journal of Archaeological science 34, 272-288

Lourakis, M., Argyros, A., 2009. SBA: A software package for generic sparse bundle adjustment. ACM Transactions on Mathematical Software 36 (1), 1-30.

Lucas G., 2001. Destruction and the Rhetoric of Excavation. Norwegian Archaeological Review 34(1), 35-46.

Mendes, C., Silva, L., Bellon, O., 2012. IMAGO Visualization System: an interactive web-based 3D visualization system for cultural heritage applications. Journal of Multimedia 7 (2), 205-210.

Pavlidis, G., Koutsoudis, A., Arnaoutoglou, F., Tsioukas, V., Chamzas, C., 2007, Methods for 3D digitization of cultural heritage. Journal of Cultural Heritage 8 (1), 93-98.

Pérez, M., Agüera, F., Carvajal, F., 2013. Low cost surveying using an unmanned aerial vehicle. International Archives of Photogrammetry and Remote Sensing and Spatial Information Sciences 40 (1/W2), 311-315. 
Plets G., Gheyle W., Verhoeven G., De Reu J., Bourgeois J., Verhegge J., Stichelbaut B., 2012a. Towards a Three-Dimensional Registration of the Archaeological Heritage of the Altai Mountains. Antiquity, 86(333): 884-897.

Pollefeys M., Koch R., Vergauwen M., Van Gool L., 2000. Automated reconstruction of 3D scenes from sequences of images. ISPRS Journal of Photogrammetry and Remote Sensing, 55(4), 251-267.

Pollefeys M., Van Gool L., Vergauwen M., Cornelis K., Verbiest F., Tops J., 2003. 3D recording for archaeological fieldwork. Computer Graphics and Applications, IEEE, 23(3), 20-27.

Remondino, F., 2011. Heritage recording and 3D modeling with photogrammetry and 3D scanning. Remote Sensing 3 (6), 1104-1138.

Robertson, D., Cipolla, R., 2009. Structure from motion, in: Varga, M. (Ed.), Practical image processing and computer vision. John Wiley, Hoboken, NJ, USA., p. 49.

Rottensteiner, F., Trinder, J., Clode, S., Kubik, K., 2007. Building detection by fusion of airborne laser scanner data and multi-spectral images: performance, evaluation and sensitivity analysis. ISPRS Journal of Photogrammetry and Remote Sensing 62 (2), 135-149.

Rua, H., Alvito, P., 2011. Living the past: 3D models, virtual reality and game engines as tools for supporting archaeology and the recontruction of cultural heritage: the case-study of the Roma villa of Casa de Freiria. Journal of Archaeological Science 38 (12), 3296-3308.

Shashua, A., Werman, M., 1995. Trilinearity of three perspective views and its associated tensor, Fifth International Conference on Computer Vision. IEEE, Boston, MA, USA, pp. 920-925.

Seitz, S., Curless, B., Diebel, J., Scharstein, D., Szeliski, R., 2006. A comparison and evaluation of multi-view stereo reconstruction algorithms, IEEE Computer Society Conference on Computer Vision and Pattern Recognition, New York, NY, USA, 122 June, pp. 519-528

Tack, F., Debie, J., Goossens, R., De Meulemeester, J., Devriendt, D., 2005. A feasible methodology for the use of close range photogrammetry for the recording of archaeological excavations, Proceedings of the CIPA 2005 XX International Symposium, Torino, Italy, pp. 561-565.

Tack, F., Buyuksalih, G., Goossens, R., 2012. 3D building reconstruction improvement based on given ground plan information and surface models extracted from spaceborne imagery. ISPRS Journal of Photogrammetry and Remote Sensing 67 (1), 52-64.

Traxler, C., Neubauer, W., 2008. The Harris matrix momposer: a new tool to manage archaeological stratigraphy, in: Börner W., U.S. (Ed.), Archäologie und Computer: Kulturelles Erbe und Neue Technologien, Vienna, Austria, pp. 12 (on CD-ROM) 
Van Liefferinge, K., Docter, R., Pieters, T., van den Eijnde, F., 2011a. The excavation of Cistern no.1 at Thorikos, in: Docter, R., De Wulf, A., Monsieur, P., van den Eijnde, F., van de Put, W., Van Gelder, K. (Eds.), Thorikos 10, Reports and Studies. University Press, Ghent, Belgium.

Van Liefferinge, K., Stal, C., De Wulf, A., 2011b. The Thorikos excavations 1963-2010 in maps, in: Docter, R., De Wulf, A., Monsieur, P., van den Eijnde, F., van de Put, W., Van Gelder, K. (Eds.), Thorikos 10, Reports and Studies. University Press, Ghent, Belgium.

Van Liefferinge, K., van den Berg, M., Stal, C., Docter, R., De Wulf, A., Verhoest, N., 2014. Reconstructing the position of Thorikos in the Laurion silver mining district (Attica, Greece) through hydrological analyses. Journal of Archaeological Science 41, 272-284.

Verhoeven, G., 2011. Taking computer vision aloft - archaeological three-dimensional reconstruction from aerial photographs with PhotoScan. Archaeological Prospection 18 (1), 673.

Verhoeven G., Taelman D., Vermeulen F., 2012. Computer vision-based orthophoto mapping of complex archaeological sites: the ancient quarry of Pitaranha (Portugal-Spain). Archaeometry, 54(6), 1114-1129.

Verhoeven, G., Doneus, M., Briese, C., Vermeulen, F., 2012. Mapping by matching: a computer vision-based approach to fast and accurate georeferencing of archaeological aerial photographs. Journal of Archaeological Science 39 (7), 2060-2070.

Wang, L., Kang, S., Szeliski, R., Shum, H., 2001. Optimal texture map reconstruction from multiple views. IEEE Computer Vision and Pattern Recognition 1 (1), 1-8.

Zhukovsky, M., 2002. Handling digital 3-D record of archaeological excavation data. Archaeological Informatics: Pushing the Envelope. CAA2001, BAR International Series 1016, 431-438. 